\title{
Chapter 11 \\ Best Practices and Challenges to Sex Worker Community Empowerment and Mobilisation Strategies to Promote Health and Human Rights
}

\author{
Cynthia Navarrete Gil, Manjula Ramaiah, Andrea Mantsios, \\ Clare Barrington, and Deanna Kerrigan
}

\section{Community Empowerment Among Sex Workers: Principles and Approach}

Community empowerment is an approach where sex workers come together to generate solidarity and mobilise their collective power to address structural barriers to their health and human rights [1]. In this process, sex worker communities seek allies-including governmental and non-governmental groups-as well as challenge institutions and individuals who inhibit progress towards social and policy change [1]. Community empowerment is a social process or movement. It is also a crucial component of effective planning, implementation, and monitoring of rightsbased programming to address the health and human rights of sex workers [2]. Components of a comprehensive, community empowerment approach in the con-

\author{
C. Navarrete Gil \\ APROASE, México City, Mexico \\ e-mail: aproase@gmail.com \\ M. Ramaiah \\ Ashodaya Samithi, Mysore, India \\ e-mail: ramaiah.manjula008@gmail.com
}

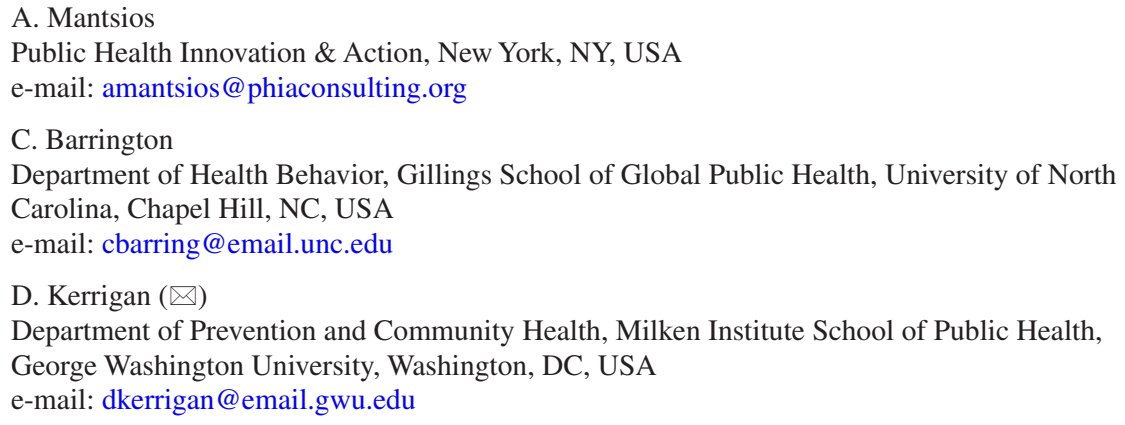


text of HIV prevention may include sex worker-led outreach and peer education and navigation; community-led drop-in-centres; community mobilisation and sex worker advocacy to promote socio-economic rights and opportunities; access to legal services and support; and improved sexual and reproductive health services tailored to the needs of sex workers.

Community empowerment approaches recognise sex work as work and as a profession. They aim to ensure the labour and human rights of sex workers, including their right to health, rather than trying to rescue or rehabilitate them [3]. Organising into sex worker-led groups is an effective strategy for sex workers to collectively challenge structural barriers such as stigma, discrimination, violence, and other forms of social inequality such as gender-related inequalities $[4,5]$.

Legal and policy environments often limit the reach and potential impact of sex worker groups. For example, structural constraints such as criminalisation may restrict the ability of sex workers to organise, thus challenging community empowerment efforts [6]. Despite these barriers, sex worker groups have formed and been sustained in multiple geographic regions to address the broader needs of the community. There are well-documented examples of such groups in South Asia [7-13], where community empowerment efforts among sex workers have received comparatively substantial resource investments as part of large-scale targeted HIV prevention efforts from external donors. This has also been the case in Latin America and the Caribbean [14-16]. Implementation and evaluation of community empowerment approaches among sex workers in other regions, such as sub-Saharan Africa, have been less common but are slowly increasing in places like South Africa, Kenya, and Tanzania [17].

\section{Impact of Community Empowerment Among Sex Workers on HIV and Health Outcomes}

Based on the evidence and outcomes from earlier programmes from South Asia, community empowerment is recognised as a best practice effectively addressing the health and human rights of sex workers $[5,9,10,18]$, and was acknowledged as a critical component for programming by the Joint United Nations Programme on HIV/AIDS investment framework [19]. In 2013, guidance on implementing sex worker-led, rights-based programming aimed at empowering sex workers was provided in the World Health Organization (WHO)-led, multi-agency collaborative document, and tool entitled "Implementing Comprehensive HIV/STI Programmes with Sex Workers: Practical Approaches from Collaborative Interventions”, the document is also known as the Sex Worker Implementation Tool (SWIT) [3].

Two years later, the Global Network of Sex Work Projects (NSWP) conducted a case study to measure the impact of the SWIT and found that sex worker-led groups around the world were using this guidance as they successfully implemented rightsbased programming, ramped up advocacy efforts, and held trainings to build capac- 
ity among other sex worker groups [2]. NSWP has committed to supporting global and regional sex worker networks in building capacity at regional, national, and local levels to advocate for rolling out the SWIT, given what a powerful tool it has proved to be for sex worker organisation and mobilisation across settings.

Given the scientific evidence supporting its impact, community empowerment has increasingly gained recognition as a key approach for addressing HIV among sex workers $[6,20]$. A systematic review and meta-analysis of the effectiveness of community empowerment approaches among female sex workers found that these programmes were associated with a $32 \%$ reduction in HIV infection, significantly decreased odds of sexually transmitted infections (STI), and about a three-fold increase in the odds of consistent condom use between female sex workers and their clients across geographic settings [1]. The most well-known examples of community empowerment approaches to HIV prevention come from India, starting with the Durbar Mahila Samanwaya Committee. This organisation, begun as part of the Sonagachi Project [7], is a community-driven initiative that achieved significant increases in consistent condom use and reductions in HIV prevalence among brothel-based female sex workers in Kolkata [21-23].

The Avahan India AIDS Initiative [24], building on the experiences of Sonagachi, developed and implemented a multi-level intervention package that included peermediated approaches as well as STI services to address structural and environmental barriers to HIV prevention among sex workers across several states in India. The Avahan programme also achieved significant increases in consistent condom use between sex workers and their partners, and decreases in the prevalence of STI among female sex workers exposed to the programme [11, 25, 26].

In the Dominican Republic, two similar efforts including Compromiso Colectivo (Collective Commitment) and later Abriendo Puertas (Opening Doors), included community empowerment approaches, and were successful in improving consistent condom use as well as HIV care engagement and antiretroviral therapy (ART) adherence [16, 27-29]. Additionally, in Brazil, Project Encontros (Coming Together) used clinical and social intervention strategies, including peer education and community outreach, to reduce HIV/STI rates and encourage adoption of consistent condom use among sex workers. Among women in the Encontros programme, decreased unprotected sex was associated with increased social cohesion and participation in social networks [14]. In sub-Saharan Africa, fewer examples have been documented and are notably absent from peer-reviewed scientific literature. Project Shikamana (Let's Stick Together) in Iringa, Tanzania is one such example, however. Project Shikamana is a randomised controlled trial of a community-driven combination prevention model, which significantly reduced HIV incidence and improved HIV care and treatment outcomes among female sex workers living with HIV [3032]. Additional examples from the practice-based literature include the work of Sisonke in South Africa and Bar Hostess Empowerment and Support Programme in Kenya, where sex worker groups have been formed and sustained over a number of years and have mobilised to address both HIV and other health and human rights concerns such as gender-based violence [17]. 
While more limited research has been conducted on the impact of community empowerment approaches among male and transgender sex workers, promising community-led models have been established. One of these is HOYMAS (Health Options for Young Men on HIV/AIDS/STI), a male sex worker-led organisation in Kenya [33]. HOYMAS has worked to respond to the unique vulnerabilities of male sex workers in their settings and sought to help inform models of tailored HIV prevention services elsewhere [33, 34]. Another example, Sex workers IN Group (SWING), is a Thai organisation working within male and transgender sex worker communities driven by the principles of community ownership and community representation [35]. SWING focuses on empowerment through education, aiming to improve quality of life for its members and to enhance their abilities to participate in local and national sex worker movements as peer leaders. South Africa's Sex Workers Education \& Advocacy Taskforce (SWEAT), co-founded by a male sex worker and committed to working with all adult sex workers, focuses on community development and engaging sex workers in issues related to health and legal reform [24]. SWEAT's work includes the launching of the above mentioned Sisonke, a sex worker movement to unite sex workers, improve living and working conditions of sex workers, and fight for equal access to rights [36].

Beyond HIV, community empowerment approaches have an important role in addressing violence, safe work environments, and economic stability for sex workers. Community-driven, multi-level interventions among female sex workers have successfully reduced their risk for HIV and violence in India [37-39]. These interventions, implemented as part of the Avahan initiative, have responded to female sex workers' risks for intimate partner violence as well as from clients and police. Grounded in the concepts of collectivisation and the development of critical thinking and dialogue, these interventions included components such as trainings led by human rights lawyers educating sex workers on their rights and helping them bring perpetrators to justice. These programmes focus on shifting norms around the acceptability of violence, while challenging gender roles and encouraging new relationship models based on gender equity and respect $[13,38]$.

Community-led economic empowerment strategies, including co-operative banking and savings and loan mechanisms for female sex workers, have increased financial security and improved social and economic outcomes. They have also contributed to reducing sexual risk behaviours. The co-operative bank of the aforementioned Durbar intervention, the Usha Multi-purpose Co-operative Society, improved economic status among programme participants by increasing savings and reducing the economic vulnerability that can affect the capacity of sex workers to negotiate condom use with clients $[4,5,40]$. Pragati, another multi-component intervention among sex workers in India, combined a co-operative bank structure that provided a savings and credit mechanism with community mobilisation and peer-based HIV prevention activities [41]. The programme significantly decreased incidence of STI, increased reported condom use at last paid sex [42], and documented over 3000 sex workers joining as shareholders of the co-operative bank, with more than half of them opening savings accounts [41]. In Iringa, Tanzania, female sex workers who participated in community savings groups were found to have nearly two times 
greater odds of consistent condom use with new clients, compared to those who did not participate in such groups [43]. These examples highlight the important role cooperative banks and savings groups can play in reducing sexual risk behaviours and underscore the importance of comprehensive community-led interventions to address financial insecurity among sex workers.

The body of literature on community empowerment approaches for addressing HIV and other health outcomes among sex workers illustrates the effectiveness of utilising these strategies to effectively address the social and structural vulnerabilities facing sex workers. This evidence has generated calls for additional work to gather evidence on this strategy's potential impact on other aspects of the health and human rights of sex workers. For example, NSWP has specifically identified critical gaps in the literature on community empowerment approaches, including its effectiveness as a strategy for addressing economic vulnerability and promoting financial security of sex workers [44].

The two case studies detailed below highlight both best practices and challenges of community empowerment efforts led by sex workers in two distinct sociopolitical and cultural contexts: India and Mexico. The studies offer an in-depth look at strategies designed and implemented by sex worker groups to address human rights violations, advocate for health, and respond to punitive legal environments. By examining these dynamic processes, we explore existing successes as well as continued gaps in achieving sustained progress towards upholding the health and human rights of sex workers across different settings. The case studies were developed by sex worker leaders of local organisations in each of these settings. They reflect firsthand perspectives and focus on the lived experiences, realities, and collective responses among sex workers.

\section{Mobilising the Sex Worker Community in Mysore, India: Ashodaya Samithi Case Study}

Our case study describes our process of community empowerment in response to the HIV epidemic as well as other challenges that we face as sex workers in our environment. This story begins in 2004, when a technical team of public health experts and researchers from the University of Manitoba visited Mysore, India- a bustling tourist destination with a vibrant sex work industry-to design and implement an HIV prevention programme with sex workers as part of the Avahan India AIDS Initiative. At that time, sex workers in Mysore generally operated from the streets and faced many day-to-day challenges: police raids, extortion on the part of police, and violence, from police, pimps, and boyfriends, among others. We were initially cautious of the technical team as it was difficult for us to trust outsiders, given all of the stigma, discrimination, and abuse we were exposed to. However, the technical team spent time with us and engaged in conversations about our lives and our well-being. They also provided unconditional crisis support, including when 
our fellow sex worker sisters were detained by police during a raid or when we were refused health care at a government facility. This combination of taking the time to get to know us along with advocating for and supporting us, facilitated a process of trust and collaboration grounded in our interests. This created a foundation for further sex worker organising and mobilisation around our rights and needs.

Over time, sex workers from our community started meeting in small groups, identifying themselves around their shared profession, problems, concerns, and life experiences. Through these meetings and what became daily conversations with the technical team, we were encouraged to think about our lives, dreams, and aspirations, and we began to realise that we were not alone. Through these dialogues, sex workers in Mysore began to understand sex work as work and not something that we needed to be ashamed of, which was a new and empowering concept for many of the women in our community.

Several sex workers joined the technical team as volunteers and were asked to provide insights into the community's needs. This process was critical to garnering community interest and identifying a rallying point for our sustained community mobilisation. The sex workers identified three priorities for our community: the first was addressing police violence, as sex workers were experiencing serious and regularly occurring violence from the police. The second was the establishment of safe spaces-since most sex workers operated from the streets at that time, they had nowhere to sleep, rest, or freshen up. We spent most of our free time in parks and on the street, and the local thugs and police would take our money, harass, and rape us. The third was access to health services; we lacked a clinic for sex workers where we could access respectful, quality services at accessible hours.

The sex workers who volunteered with the technical team started going to the field, talking to their friends about the problems they were facing, and, once they opened, began bringing them to the safe space and the clinic. These were critical steps in mobilising the community. These steps marked the beginning of our organisation, Ashodaya Samithi (Dawn of Hope), as sex workers in Mysore began to come together. Through that process, mutual trust and awareness were generated among the community members who were ready to listen, learn, and implement collective actions related to working towards better health for sex workers. As a result, Ashodaya Samithi was registered as a sex worker-led organisation, one that is by, for, and comprised of sex workers.

The governing body of Ashodaya Samithi consists of representatives from all three subpopulations of sex workers: female, male, and transgender sex workers. From our inception, we realised that our sex work circuits (the client base of these three subpopulations) overlapped. This is why there has always been a strong bond and mutual understanding and support among the female, male, and transgender sex worker community in Mysore. Hence, when we came together to form our own organisation, we decided that it would comprise female, male, and transgender sex workers. However, over the years we realised that, although we have some issues in common, there are many other challenges and issues specific to male and transgender sex workers. The male and transgender sex workers formed their own collective called Adasha, which functions under the broad umbrella of Ashodaya. While we 
address most sex workers' issues as a unit, Adasha takes up issues specific to male and transgender sex workers.

Ashodaya Samithi leadership came to understand that community mobilisation is an ongoing process and that social cohesion is key to sustaining this process. Over the years, as women's circumstances changed, so did our needs. From the early demand for a safe space to rest during the day, the needs shifted to include wanting to provide our children with a good education, to build our own houses, and to save money for the future. Ashodaya Samithi was committed to helping facilitate solutions to each of these demands. We partnered with the Women and Child Welfare Department (WCD) of the Government of Karnataka to enrol sex workers' children in boarding schools, free of cost. Our organisation has also led the process of registering and issuing national identity documents for sex workers, which are essential for accessing social benefits.

We have also supported the establishment of a co-operative society to address the financial needs of our community. The co-operative society was set up with support from Ashodaya Samithi and was registered as an independent entity in November 2013. It is run and managed by an independent, 11-member board of directors who are all sex workers. The co-operative society provides low-interest loans and flexible payment schedules. This provides sex workers with a reliable place to save their money, enabling them to plan for the future. The savings account holders are also shareholders in the co-operative and benefit from the dividend payments made out of the co-operative's profits.

While these were some of the immediate needs that brought the sex worker community together in Mysore, other hard-hitting realities continued to keep the community tight-knit and working together. The first Integrated Behavioural and Biological Assessment (IBBA), conducted in August-September 2004, revealed $26 \%$ HIV prevalence among female sex workers in Mysore city. The realisation that one in four sex workers was living with HIV created a sense of alarm. Understanding that one person alone cannot control the spread of HIV forced the community to think critically about possible solutions we could embark on together.

Sex workers started holding community meetings to speak about HIV as an issue affecting their community and families. The discussions focused on finding ways to protect all sex workers from HIV infection. This process led us to reach the onepoint agenda of "No Condom. No Sex". We began spreading the "No Condom. No Sex" message through street plays and other community events. This message became a community norm and all sex workers in the community were urged to follow it. There was general recognition that there were problems common to all that could only be addressed if we confronted them together.

The initial challenges that inspired community mobilisation of sex workers in Mysore included police violence and raids, stigma and discrimination, and violence and exploitation. We were constantly harassed and abused by police, sexually, physically, and verbally, and we were forced to pay fines and to provide sex without being paid. Stigma and discrimination came in many forms, including from doctors and nurses at hospitals and clinics who treated us poorly. Sex workers were required to get an HIV test before receiving any other clinical examination. In some cases, 
this resulted in their deaths, as staff refused to provide emergency treatment without first seeing a patient's HIV test result.

Female sex workers also experienced violence and exploitation from various perpetrators including boyfriends, partners, "pimps", and thugs on the street. Female sex workers, closely controlled by boyfriends and "pimps", experienced violence in different forms. We often had to give these men a portion of our daily income, and they would prevent us from partaking in any activity that would compromise our earnings. Many sex workers struggled with low self-esteem and lack of personal and collective agency and empowerment. Reflecting the pervasive nature of stigma surrounding sex work, we were scared of expressing our problems to others and worried that our families and friends would discover we were sex workers and disown us.

To address these challenges and build on our foundation of empowerment, sex workers continued to work together to affect change at multiple levels including the following:

Self-respect and self-esteem: First with the technical team and then within the sex worker community, we worked to create authentic and critical dialogue around the issues of who we are and what we think about ourselves. This process helped us to build self-esteem and believe that our work was of no less worth than other work.

Crisis response system and team: Building on the unconditional, 24/7 crisis support that the technical team offered in response to police incidents or episodes of violence, we created our own crisis response team, providing around-the-clock crisis support to our community members. Our peer first responders in different areas can be mobilised to respond to violence and other crises. We have also created a system of "crisis mitigation", where we recognise potential threats and work to neutralise the threat before it creates a problem.

Multi-level advocacy: Once we had become organised, we undertook advocacy at various levels. Teams of sex workers approached the local police constable, shopkeepers, and healthcare providers to sensitise them about who we are and our needs and struggles as sex workers. We started working in partnership with the police department to organise trainings about how to create enabling environments to promote the health and well-being of sex workers.

Healthcare navigators: Stigma and discrimination inflicted by doctors and nurses was a historical and ongoing problem for female sex workers in Mysore so we trained sex worker healthcare navigators to work in healthcare settings and form working relationships with the providers to improve access and quality of care. These healthcare peer navigators served as a bridge between the healthcare providers and the community to ensure access to respectful services.

Boyfriends' Club: The Boyfriends' Club was an initiative to engage and educate our intimate partners on the challenges facing sex workers, including violence, harassment over money, and negotiation of safe sex behaviours. Boyfriends/husbands and other regular partners were identified as major perpetrators of violence, and a collective roadblock for women wishing to participate in our 
programmes. These men strongly influenced members' decision-making around condom and contraceptive use. It became clear that we needed to work with them. Our work with partners helped to neutralise some of the barriers they had presented and enabled women to become part of our larger network of people who could respond to crises among sex workers.

The Integrated Behavioural and Biological Assessment (IBBA), carried out in 2004, provided baseline data on HIV-related outcomes among female sex workers in Mysore city prior to the start of Ashodaya Samithi's concerted intervention efforts. In 2006, another IBBA measured the same indicators after the implementation of Ashodaya activities in the sex worker community. This allowed for pre- and post-assessments, as shown in Table 11.1 [8]. All STI measures declined significantly during this period, and condom use at last sex increased significantly with all different partner types. HIV prevalence remained stable over this period $(26 \%$ and $24 \%$ ). However, a detuned assay (a testing method designed for the purpose of HIV incidence estimation) suggested a decline in recent HIV infections during this time [8].

Indicating the sustained effect of this earlier impact over time, the DIFFER Study (Diagonal Intervention to Fast-Forward and Enhance Reproductive Health), conducted between 2011 and 2016, documented continued improvements in sex workers' condom use and STI outcomes.

Ashodaya Samithi has identified several goals and next steps for our future community-led action. We have set up a community-led academy (Ashodaya Academy), through which we provide hand-holding support to other community-based organisations engaged in the process of successfully working with sex workers to address their health challenges. We have supported organisations in the sub-Saharan Africa and Asia-Pacific regions, including providing technical expertise in setting up the Sex Workers Academy of Africa (SWAA) in collaboration with another sex workerled organisation, VAMP from India and NSWP. Ashodaya aims to further disseminate our experiences and the lessons we have learned to help facilitate more community-led responses in other settings. Ashodaya also aims to branch out from just HIV prevention services into awareness, prevention, detection, care, and support regarding other diseases, including tuberculosis.

Table 11.1 Pre-post Ashodaya Samithi implementation changes in HIV-related indicators [8]

\begin{tabular}{l|l|l}
\hline & $\begin{array}{l}\text { IBBA, 2004 } \\
(\text { Baseline, } n=429)(\%)\end{array}$ & $\begin{array}{l}\text { IBBA, 2006 } \\
(\text { Follow-up, } n=425)(\%)\end{array}$ \\
\hline HIV prevalence & 26 & 24 \\
\hline Syphilis infection & 25 & 12 \\
\hline Trichomonas & 33 & 14 \\
\hline Gonorrhoea & 5 & 2 \\
\hline Chlamydia & 11 & 5 \\
\hline Condom use with occasional clients & 65 & 90 \\
\hline Condom use with repeat clients & 53 & 66 \\
\hline Condom use with regular partners & 7 & 30 \\
\hline
\end{tabular}


While still integrating sexual and reproductive health and rights (SRHR) initiatives into its existing service provision, the organisation further aims to expand SRHR initiatives on a larger scale to create a more holistic approach to health. Resource constraints have made it more challenging for Ashodaya Samithi to operate, particularly since the end of the Avahan initiative, but we continue to work to mobilise resources from different sources to sustain initiatives responding to the needs and interests of the sex worker community.

\section{Addressing Institutional Violence and Punitive Laws in Mexico: APROASE Case Study}

Established in Mexico City in 1984, APROASE (Asociación en Pro Apoyo a Servidores) was the first civil organisation formed and led by sex workers, with the mission of advocating for and defending the health, labour, and human rights of sex workers. We were legally recognised in 1997 and opened a sex worker friendly health clinic offering HIV testing, medical care for STI, gynaecological exams, and reproductive health services.

While still mostly providing services to sex workers, in an effort to reduce stigma and generate more resources, we expanded our clinic in 2004 to serve the general public. Sex workers who were members of APROASE received medical services free of charge. Other sex workers who were not APROASE members were granted a subsidy from $50 \%$ to $100 \%$, depending on their economic situation. Those who were not sex workers could access clinic services by paying in full. These fees covered the expenses of those who could not cover their medical care at the time. Many of the treatments and consultations were subsidised by federal and state government financing projects.

In addition to operating the clinic, we facilitated trainings for peer educators on HIV/STI prevention and crime in the workplace and stimulated the exchange of lessons learned within the sex worker community. With financial support from the Mexican government, we developed a model for effective partnership between civil society organisations and the government to promote the health of key populations and the community.

In addition to providing health services, for over two decades we have struggled to gain recognition of sex work as a profession and to guarantee the human and labour rights of sex workers; concepts that are central to the effectiveness and sustainability of community empowerment efforts. One of the main issues APROASE addresses is clarifying the distinction between sex work and human trafficking. This distinction has been complicated by international protocols, laws, and agreements conflating the two. As a result of this conflation, in many settings (including Mexico), sex workers are barred from their constitutional rights related to labour and health, and are excluded from legal protection and the freedom to self-organise. Our case study highlights how the misinterpretation and manipulation of laws 
related to human trafficking ultimately led to the closure of our community-based clinic, and essentially forced our organisation to cease our community-led health and mobilisation efforts.

In 2000, the United Nations issued the "Protocol to Prevent, Suppress and Punish Trafficking in Persons, Especially Women and Children" [45]. Known as the "Palermo Protocol", it is intended to prevent and combat trafficking of persons, to protect and help trafficking victims, and to promote cooperation among the States that are part of it. Mexico signed the Palermo Protocol in 2000, and in 2007 enacted the Mexican Law to Prevent and Punish Trafficking in Persons. Article 10 of this law defined trafficking in persons as "any act or intentional omission of one or several persons to capture, engage, transport, transfer, retain, deliver, receive, or accommodate one or more persons for the purpose of exploitation" [46].

The law did not distinguish between sex work and trafficking, nor did it mention coercion or its opposite-willingness to engage freely in organising and contracting with third parties to guarantee the security of sex workers in their places of work. As a consequence of this poorly defined law, sex workers in Mexico were denied constitutional rights as workers, and sex worker leaders were subject to unjust application of legislation related to human trafficking.

In 2012, the General Law to Prevent, Sanction, and Eradicate Crimes Related to Trafficking in Persons was published in Mexico, which significantly changed the country's definition of human trafficking [47]. Under the earlier law and within the Palermo Protocol, "acts", "means", and "purpose" are defined as the three elements of human trafficking. The new law passed in 2012, however, eliminates the "means" and only considers "acts" and "purpose" as the key elements of trafficking in persons [48]. By removing the means, trafficking becomes one of many forms of exploitation. The definition of trafficking in Article 10 of this 2012 Mexican law includes "prostitution" and other forms of sexual exploitation among the categories it identifies as human trafficking.

As a result of these laws conflating sex work and trafficking, venues where sex workers are found, such as bars, have closed following constant raids to rescue victims of human trafficking and defendants of sexual exploitation. This has compelled sex workers from those establishments to work in the streets, where they lack social organisation and security measures to protect them from violence and extortion.

While sex work is not a crime in Mexico, it is not officially recognised as an occupation, either. Another civil society organisation, called Brigada Callejera en Apoyo a la Mujer "Elisa Martínez" (Street Brigade in Support of Women "Elisa Martinez"), advocates for the human, civil, and labour rights of sex workers. They effectively negotiated with authorities in Mexico City to establish a system of credentials for sex workers, providing them with some formal recognition as workers' protections to compensate for their lack of legal protection. This negotiation is a great example of innovation and achievement in the face of a very challenging and ambiguous legal context. Unfortunately, it remains the exception rather than norm with regard to sex worker mobilisation in Mexico.

Despite the important work of the Brigada Callejera, the lack of formal recognition of sex work as work facilitates ongoing institutional violence against sex work- 
ers because they are not protected as workers, by the constitution or any other legislation. One example of the unjust application of the trafficking law is the case of our founding director, Alejandra Gil. She was arrested by Mexican law enforcement authorities in March 2014 and accused of engaging in human trafficking activities based on the very laws and legal interpretations that conflate sex work with trafficking. She is currently serving a 15-year prison sentence.

Part of APROASE's work is to protect the rights of sex workers. Before Mexico's anti-trafficking law was signed into law in 2007, Alejandra and other sex workers developed and signed an agreement with neighbours and authorities in the Sullivan neighbourhood of Mexico City where they worked. In it, they defined the roles and responsibilities of all parties involved. It included clauses prohibiting violence towards sex workers by clients, substance use in the workplace, and participation of anyone under 18 in sex work. These measures, however, were ultimately trumped by the misapplication of the subsequent trafficking legislation and its use to justify the accusations lodged against Alejandra. Local law includes coercion as a condition for considering someone to be involved in the trafficking of persons, however, coercion was not proven in her case nor was evidence to the contrary taken into account in the trial. The prosecution's conflation of sex work and human trafficking, along with the lack of a clear definition of coercion in the law, allowed the evidence to be ignored. These factors led to the court failing to recognise sex work as work and to the reinforcement of sex workers' stigmatised status.

The arrest of APROASE Director Alejandra Gil was rife with stigma and discrimination as the media manipulated the case as a triumph of the Mexican authorities over human trafficking. Television and newspaper coverage showed images of Alejandra's face. Without any consideration of the possibility of her innocence, the press declared her guilty before she had even been sentenced, further violating the rights to which she was denied access, and further illustrating the social injustice experienced by sex workers as a result of punitive laws and a context of stigma and discrimination.

Following Alejandra's arrest, APROASE became the victim of media violence, extortion, police harassment, and death threats. The impact of these events on the organisation has been far-reaching. We have closed APROASE and no longer have a safe space to meet or conduct workshops. The situation overall has been devastating and stigmatising, to the point where no lawyer wants to take on the case for fear of being linked to human trafficking.

Alejandra's case is emblematic of the highly punitive legal environment that conflates sex work and trafficking in Mexico, and how this directly impacts the ability of sex workers to meaningfully and safely organise and advocate for improved labour, health, and human rights.

Based on our experience, we argue that it is necessary for government authorities at all levels to recognise that sex workers organising themselves as a community does not in any way equate with or indicate engagement in coercion or sexual exploitation. Sex workers have the right to work and be protected. A critical next step is to work with the Mexican government to review and amend the laws against human trafficking to ensure they differentiate between sex work, which is, by defini- 
tion, consensual, and trafficking. It is necessary to design and implement strategies in conjunction with both the federal and state governments to ensure the recognition of sex work as a legitimate occupation, and to guarantee the fulfilment of sex workers' constitutional rights. This work is essential to protect human rights; ensure our country's ability to contribute to successful programmes for the prevention of HIV and other STI; and to deal justly with the occupational violence experienced by sex workers. Once these amendments have been made, sex workers can partner with the government to work collaboratively on improving health conditions and ensuring safe workplaces for sex workers, as well as empowering them to exercise their constitutional right to form civil organisations or unions as protected by the constitution. As long as sex work is not recognised as labour, sex workers will continue to be seen only as victims of trafficking, limiting community empowerment efforts.

\section{Discussion}

Community empowerment is a critical component of efforts to address the multiple social determinants of health and well-being experienced by sex workers across the world. The case studies from India and Mexico highlight multiple challenges related to community empowerment and mobilisation among female sex workers, from the interpersonal to the structural level, as well as illustrating effective strategies sex worker-led groups have devised to confront these obstacles.

Among the key principles and processes of community empowerment-based approaches is the recognition of sex work as work [49]. As reflected in both case studies, developing a critical consciousness enabling sex workers to understand the structural causes of their vulnerability and marginalisation is essential to the process of mobilising for collective action [1]. Community empowerment approaches facilitating critical consciousness and the agency to take up collective action can promote mobilisation of sex worker communities to bring about social and structural change [50].

There are multiple structural barriers facing sex workers and their ability to organise and mobilise within their communities. These include labour rights violations, financial insecurity, institutional and interpersonal violence, criminalisation and punitive laws, and stigma and discrimination. The literature on existing programmes and the case studies presented here support the use of community empowerment approaches, based within a health and human rights framework, to holistically address these multi-level barriers. Through social justice-oriented movements, sex workers will be able to advocate for their rights to health, freedom from violence, socio-economic opportunities, and safe working conditions and environments.

The experiences of Ashodaya Samithi illustrate interpersonal and structural challenges to sex worker organising and mobilisation, such as police violence and raids, stigma and discrimination, violence and exploitation by different perpetrators, and lack of personal and collective agency among sex workers in Mysore. In the face of these major challenges, by bringing the community together, the programme identi- 
fied solutions. Using a community mobilisation and empowerment approach including peer-led outreach and increasing access to and utilisation of health services, the programme has achieved significant impacts including substantial increases in selfreported condom use with all sexual partners, and significant reductions in the prevalence of STI, including HIV, among female sex workers [8]. The programme has also had a significant impact on structural violence experienced by sex workers in Mysore [8, 12]. In interviews conducted as part of qualitative research with Ashodaya sex workers, women expressed that violence from the police has been reduced [12]. Ashodaya programme monitoring data likewise showed a marked reduction in violence from the police [8]. Other community-based organisations in India have demonstrated that sex workers who are mobilised to prevent HIV can also effectively develop strategies to monitor and reduce harmful policing practices [51].

Ashodaya has implemented effective strategies for confronting interpersonal violence experienced from partners and clients (including the Boyfriends' Club mentioned in the case study), working to address the challenges presented by the male partners of women participating in the programme, who are threatened by their empowerment. Ashodaya Samithi is an excellent example of using the principals and approaches of community empowerment within a sex worker community to reduce structural violence and human rights violations at various levels of society.

In the case of APROASE in Mexico, we see complex legal and policy challenges creating barriers to sex worker organisation and mobilisation. As described in the case study, sex workers in Mexico are trapped in a "legal limbo" as sex work is not prohibited but also not recognised formally as an occupation [52]. As a result, there are legal grey areas including the conflation of some forms of sex work and work environments with trafficking and sexual exploitation [52]. Early on, sex worker activists identified that it would be necessary to claim the title of "sex workers", with all the stigma accompanying that label, in order to claim the recognition of their labour rights as they moved to take legal action against the government. Because of the efforts of Brigada Callejera along with the Red Mexicana de Trabajo Sexual, a credentialing process which grants licences to sex workers was established, recognising sex workers as non-wage workers and allowing them to open bank accounts or request loans on declaring their sources of income. The credentials are also a form of protection against "anti-trafficking" police raids. Attaining their licences provides sex workers with a public and legal identity in society. The efforts to recognise sex work as work in Mexico have been able to provide sex workers with health, education, and training opportunities in addition to workers' rights [52].

The legal complexities around sex work in Mexico are not unique. Similar legal and political challenges exist in settings around the globe. An increasing number of reports show how punitive laws and policies governing sex work are linked to increased HIV acquisition and transmission [6]. Modelling has shown that decriminalisation of sex work could avert 33-46\% of HIV infections across geographic and epidemic settings in the next decade [6]. Beyond associations with HIV infections, criminalisation and punitive policies towards sex work have also been shown to be 
related to increased stigma $[8,53]$, insecurity regarding food supply and finances $[54,55]$ and higher rates of inconsistent condom use [6] among sex workers.

In terms of gaps identified in this chapter, there is a lack of systematic community empowerment-based approaches and evaluations of these efforts among male and transgender sex workers. Work in this area is urgently needed to realise the potential for community empowerment interventions with diverse populations of sex workers and, specifically, to understand the particular challenges and barriers to community organisation and mobilisation these populations face in different contexts. Additionally, efforts should be made to take community empowerment efforts to scale and to conduct longitudinal evaluation research assessing changes over time, particularly examining health and rights outcomes that can take significant time to show impact.

These two case studies illustrate, as has been found in other settings including Brazil [1], the challenges that sex worker organisations face when governmental and/or international donor support dissipate. However, they also represent the importance to local sex workers' organisations of connections to regional and international networks of organisations led by sex workers. Moving forward, government and donor support is critical for health-related programme and research funding among sex workers and for broader organisation and network strengthening.

\section{References}

1. Kerrigan D, Kennedy CE, Morgan-Thomas R, Reza-Paul S, Mwangi P, Win KT, et al. A community empowerment approach to the HIV response among sex workers: effectiveness, challenges, and considerations for implementation and scale-up. Lancet. 2015;385:172-85.

2. NSWP. SWIT case study. 2015. Available from: https://www.nswp.org/resource/ swit-case-study.

3. WHO, UNFPA, UNAIDS, NSWP, World Bank. Implementing comprehensive HIV/STI programmes with sex workers: practical approaches from collaborative interventions. Geneva: World Health Organization; 2013.

4. Ghose T, Swendeman D, George S, Chowdhury D. Mobilizing collective identity to reduce HIV risk among sex workers in Sonagachi, India: the boundaries, consciousness, negotiation framework. Soc Sci Med. 2008;67(2):311-20.

5. Swendeman D, Basu I, Das S, Jana S, Rotheram-Borus MJ. Empowering sex workers in India to reduce vulnerability to HIV and sexually transmitted diseases. Soc Sci Med. (1982. 2009;69(8):1157-66.

6. Shannon K, Strathdee SA, Goldenberg SM, Duff P, Mwangi P, Rusakova M, et al. Global epidemiology of HIV among female sex workers: influence of structural determinants. Lancet. 2015;385(9962):55-71.

7. Jana S, Basu I, Rotheram-Borus MJ, Newman PA. The Sonagachi Project: a sustainable community intervention program. AIDS Educ Prev. 2004;16(5):405-14.

8. Reza-Paul S, Beattie T, Syed HU, Venukumar KT, Venugopal MS, Fathima MP, et al. Declines in risk behaviour and sexually transmitted infection prevalence following a community-led HIV preventive intervention among female sex workers in Mysore, India. AIDS (London, England). 2008;22(Suppl 5):S91-100. 
9. Blanchard AK, Mohan HL, Shahmanesh M, Prakash R, Isac S, Ramesh BM, et al. Community mobilization, empowerment and HIV prevention among female sex workers in south India. BMC Public Health. 2013;13:234.

10. Blankenship KM, West BS, Kershaw TS, Biradavolu MR. Power, community mobilization, and condom use practices among female sex workers in Andhra Pradesh, India. AIDS (London, England). 2008;22(Suppl 5):S109-16.

11. Thilakavathi S, Boopathi K, Girish Kumar CP, Santhakumar A, Senthilkumar R, Eswaramurthy $\mathrm{C}$, et al. Assessment of the scale, coverage and outcomes of the Avahan HIV prevention program for female sex workers in Tamil Nadu, India: is there evidence of an effect? BMC Public Health. 2011;11(Suppl 6):S3.

12. Argento E, Reza-Paul S, Lorway R, Jain J, Bhagya M, Fathima M, et al. Confronting structural violence in sex work: lessons from a community-led HIV prevention project in Mysore, India. AIDS Care. 2011;23(1):69-74.

13. Gurnani V, Beattie TS, Bhattacharjee P, Mohan HL, Maddur S, Washington R, et al. An integrated structural intervention to reduce vulnerability to HIV and sexually transmitted infections among female sex workers in Karnataka state, south India. BMC Public Health. 2011;11:755.

14. Lippman SA, Donini A, Diaz J, Chinaglia M, Reingold A, Kerrigan D. Social-environmental factors and protective sexual behavior among sex workers: the Encontros intervention in Brazil. Am J Public Health. 2010;100(Suppl 1):S216-23.

15. Kerrigan D, Telles P, Torres H, Overs C, Castle C. Community development and HIV/STIrelated vulnerability among female sex workers in Rio de Janeiro, Brazil. Health Educ Res. 2008;23(1):137-45.

16. Kerrigan D, Barrington C, Donastorg Y, Perez M, Galai N. Abriendo Puertas: Feasibility and effectiveness a multi-level intervention to improve HIV outcomes among female sex workers living with HIV in the Dominican Republic. AIDS Behav. 2016;20(9):1919-27.

17. NSWP. Good practices in sex worker-led HIV programming: regional report-Africa. 2014. Available from: https://www.nswp.org/resource/africa-regional-report-good-practice-sexworker-led-hiv-programming.

18. Cornish F. Empowerment to participate: a case study of participation by Indian sex workers in HIV prevention. J Community Appl Soc Psychol. 2006;16(4):301-15.

19. Schwartlander B, Stover J, Hallett T, Atun R, Avila C, Gouws E, et al. Towards an improved investment approach for an effective response to HIV/AIDS. Lancet. 2011;377(9782):2031-41.

20. Shannon K, Crago AL, Baral SD, Bekker LG, Kerrigan D, Decker MR, et al. The global response and unmet actions for HIV and sex workers. Lancet. 2018;392(10148):698-710.

21. Basu I, Jana S, Rotheram-Borus MJ, Swendeman D, Lee S-J, Newman P, et al. HIV prevention among sex workers in India. J Acquir Immune Defic Syndr. 2004;36(3):845-52.

22. Jana S, Chakraborty AK, Das A, Khodakevich L, Chakraborty MS, Pal NK. Community based survey of STD/HIV infection among commercial sex-workers in Calcutta (India). Part II. Sexual behaviour, knowledge and attitude towards STD. J Commun Dis. 1994;26(3):168-71.

23. Cohen J. HIV/AIDS in India. Sonagachi sex workers stymie HIV. Science (New York, NY). 2004;304(5670):506.

24. The Bill \& Melinda Gates Foundation. Avahan, the India AIDS Initiative - the Business of HIV prevention at Scale. New Delhi, India; 2008. Available from: https://docs.gatesfoundation.org/ documents/avahan_hivprevention.pdf

25. Mainkar MM, Pardeshi DB, Dale J, Deshpande S, Khazi S, Gautam A, et al. Targeted interventions of the Avahan program and their association with intermediate outcomes among female sex workers in Maharashtra, India. BMC Public Health. 2011;11(Suppl 6):S2.

26. Rachakulla HK, Kodavalla V, Rajkumar H, Prasad SP, Kallam S, Goswami P, et al. Condom use and prevalence of syphilis and HIV among female sex workers in Andhra Pradesh, India following a large-scale HIV prevention intervention. BMC Public Health. 2011;11(Suppl 6):S1. 
27. Research to Prevention. Abriendo Puertas: Feasibility and initial effects of a multi-level intervention among female sex workers living with HIV in the Dominican Republic. Baltimore, MD: USAID I Project Search: Research to Prevention; 2014.

28. Donastorg Y, Barrington C, Perez M, Kerrigan D. Abriendo Puertas: Baseline findings from an integrated intervention to promote prevention, treatment and care among FSW living with HIV in the Dominican Republic. PLoS One. 2014;9(2):e88157.

29. Kerrigan D, Wirtz A, Baral S, Decker M, Murray L, Poteat T, et al. The global HIV epidemics among sex workers. Washington, DC: World Bank; 2013.

30. Kerrigan D, Mbwambo J, Likindikoki S, Beckham S, Mwampashi A, Shembilu C, et al. Project Shikamana: Baseline findings from a community empowerment based combination HIV prevention trial among female sex workers in Iringa, Tanzania. J Acquir Immune Defic Syndr. 2017;74(Suppl 1):S60-8.

31. Kerrigan D, Galai N, Beckham S, Mwampashi A, Shembilu C, Gitagno D, et al. Project Shikamana: Positive effects of a phase II trial of community empowerment-based combination prevention to respond to HIV among female sex workers in Iringa, Tanzania. 22nd International AIDS Conference, 23-27 July, Amsterdam, Netherlands; 2018.

32. Kerrigan K, Mbwambo J, Likindikoki S, Davis W, Beckham S, Mantsios A, et al. Shikamana intervention significantly reduces HIV incidence amogn FSW in Tanzania. Conference on Retroviruses and Opportunistic Infections (CROI), 4-7 March, Seattle, Washington; 2019.

33. The Gay and Lesbian Coalition of Kenya. Health Options for Young Men on HIV/AIDS/STI (HOYMAS). 2016. Available from: https://www.galck.org/hoymas/.

34. Bridging the Gaps. A clinic for male sex workers in Kenya: HIV rates are dropping. Available from: https://hivgaps.org/news/a-clinic-for-male-sex-workers-in-kenya-hivrates-are-dropping/.

35. NSWP. Service Workers IN Group (SWING). Available from: https://www.nswp.org/featured/ service-workers-group-swing.

36. SWEAT. What is Sisonke? Available from: http://www.sweat.org.za/what-we-do/sisonke/.

37. Beattie TS, Bhattacharjee P, Isac S, Mohan HL, Simic-Lawson M, Ramesh BM, et al. Declines in violence and police arrest among female sex workers in Karnataka state, south India, following a comprehensive HIV prevention programme. J Int AIDS Soc. 2015;18:20079.

38. Beattie TS, Isac S, Bhattacharjee P, Javalkar P, Davey C, Raghavendra T, et al. Reducing violence and increasing condom use in the intimate partnerships of female sex workers: study protocol for Samvedana Plus, a cluster randomised controlled trial in Karnataka state, south India. BMC Public Health. 2016;16:660.

39. Beattie TS, Bhattacharjee P, Ramesh BM, Gurnani V, Anthony J, Isac S, et al. Violence against female sex workers in Karnataka state, south India: impact on health, and reductions in violence following an intervention program. BMC Public Health. 2010;10:476.

40. Fehrenbacher AE, Chowdhury D, Ghose T, Swendeman D. Consistent condom use by female sex workers in Kolkata, India: testing theories of economic insecurity, behavior change, life course vulnerability and empowerment. AIDS Behav. 2016;20(10):2332-45.

41. Euser SM, Souverein D, Rama Narayana Gowda P, Shekhar Gowda C, Grootendorst D, Ramaiah R, et al. Pragati: an empowerment programme for female sex workers in Bangalore, India. Glob Health Action. 2012;5:1-11.

42. Souverein D, Euser SM, Ramaiah R, Narayana Gowda PR, Shekhar Gowda C, Grootendorst DC, et al. Reduction in STIs in an empowerment intervention programme for female sex workers in Bangalore, India: the Pragati programme. Glob Health Action. 2013;6:22943.

43. Mantsios A, Galai N, Mbwambo J, Likindikoki S, Shembilu C, Mwampashi A, et al. Community savings groups, financial security, and HIV risk among female sex workers in Iringa, Tanzania. AIDS Behav. 2018;22(11):3742-50.

44. Network of Sex Worker Projects (NSWP). Sex work and money. Research for Sex Work 9. 2006. Available from: https://www.nswp.org/sites/nswp.org/files/research-for-sex-work9-english.pdf. 
45. United Nations Convention against Transnational Organized Crime. Protocol to prevent, suppress and punish trafficking in persons, especially women and children. New York: United Nations Convention against Transnational Organized Crime; 2000.

46. Ley General para Prevenir, Sancionar y Erradicar los Delitos en Materia de Trata de Personas y para la Protección y Asistencia a las Víctimas de estos Delitos. 2007. Available from: http:// www.diputados.gob.mx/LeyesBiblio/pdf/LGPSEDMTP_190118.pdf.

47. Ley General para Prevenir, Sancionar y Erradicar los Delitos en Materia de Trata de Personas y Para la Protección y Asistencia a las Víctimas de estos Delitos, Última Reforma DOF 19-032014; 2014.

48. Correa-Cabrera G, Sanders Montandon A. Arguments to reform Mexico's anti-trafficking legislation. Washington, DC: Wilson Center Latin American Program: Mexico Institute.

49. Kerrigan DL, Fonner VA, Stromdahl S, Kennedy CE. Community empowerment among female sex workers is an effective HIV prevention intervention: a systematic review of the peerreviewed evidence from low- and middle-income countries. AIDS Behav. 2013;17(6):1926-40.

50. Pillai P, Bhattacharjee P, Ramesh BM, Isac S. Impact of two vulnerability reduction strategies collectivisation and participation in savings activities - on HIV risk reduction among female sex workers. Bangalore, India: Karnataka Health Promotion Trust (KHPT); 2012.

51. Biradavolu MR, Burris S, George A, Jena A, Blankenship KM. Can sex workers regulate police? Learning from an HIV prevention project for sex workers in southern India. Soc Sci Med. (1982. 2009;68(8):1541-7.

52. Lamas M. An end to the shame: stigma and political participation among Mexican sex workers: Open Democracy/ISA RC-47: Open Movements; 2016 [updated 9 Dec]. Available from: https://opendemocracy.net/marta-lamas/end-to-shame-stigma-and-politicalparticipation-among-mexican-sex-workers.

53. Pando MA, Coloccini RS, Reynaga E, Rodriguez Fermepin M, Gallo Vaulet L, Kochel TJ, et al. Violence as a barrier for HIV prevention among female sex workers in Argentina. PLoS One. 2013;8(1):e54147.

54. Reed E, Silverman JG, Stein B, Erausquin JT, Biradavolu M, Rosenberg A, et al. Motherhood and HIV risk among female sex workers in Andhra Pradesh, India: the need to consider women's life contexts. AIDS Behav. 2013;17(2):543-50.

55. Saggurti N, Verma RK, Halli SS, Swain SN, Singh R, Modugu HR, et al. Motivations for entry into sex work and HIV risk among mobile female sex workers in India. J Biosoc Sci. 2011;43(5):535-54.

Open Access This chapter is licensed under the terms of the Creative Commons Attribution 4.0 International License (http://creativecommons.org/licenses/by/4.0/), which permits use, sharing, adaptation, distribution and reproduction in any medium or format, as long as you give appropriate credit to the original author(s) and the source, provide a link to the Creative Commons license and indicate if changes were made.

The images or other third party material in this chapter are included in the chapter's Creative Commons license, unless indicated otherwise in a credit line to the material. If material is not included in the chapter's Creative Commons license and your intended use is not permitted by statutory regulation or exceeds the permitted use, you will need to obtain permission directly from the copyright holder.

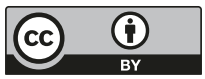

